\title{
A simple micro-ELISA method for the assay of antithyroglobulin autoantibodies in human serum
}

\author{
RICHARD GOODBURN, DAVID L WILLIAMS, VINCENT MARKS* \\ From the Ashford Hospital, London Road, Ashford, Middlesex and the *University of Surrey, Guildford
}

SUMMARY An indirect, enzyme-linked immunosorbent assay is described for the assay of thyroid autoantibodies, particularly those directed against thyroglobulin. The method is specific, sensitive and precise, and may be automated. The results are shown to correlate well with those obtained by the haemagglutination method.

The occurrence of antibodies directed against thyroglobulin has been well demonstrated in the blood of patients with autoimmune thyroid disease. ${ }^{1-3}$

Thyroid autoantibodies have been investigated classically by means of precipitin reactions, ${ }^{2}$ latex fixation, ${ }^{4}$ immunofluorescence ${ }^{56}$ and haemagglutination. ${ }^{7}$ More recently, radioassays have also been used. ${ }^{8}{ }^{9}$ However, all of these methods have drawbacks. The precipitin reaction, by which the antibodies were first demonstrated, has taken a number of forms, including radial immunodiffusion, ${ }^{2}$ counter immunoelectrophoresis ${ }^{10}$ and double diffusion. ${ }^{11}$ These methods show up to three precipitin reactions, but are generally not quantitative, and their lack of sensitivity makes them useful only in the later, lymphocytic, stages of thyroid disease.

Latex fixation has now been superseded by the haemagglutination method. Immunofluorescence is a technique which can have high sensitivity and specificity. However, the method requires sections cut from thyrotoxic thyroid glands removed at thyroidectomy, and the use of ultraviolet fluorescence microscopy (although the newer techniques with enzymelabelled antibody or the peroxidase/antiperoxidase system allow the use of normal microscopy). The technique is also non-quantitative, and requires experience for good assessment of results.

Haemagglutination is very sensitive but is subjectively assessed, and requires some experience for interpretation. It will only detect those antibodies which possess agglutinating properties, and reports have recently appeared ${ }^{12}$ on the occurrence of an agglutination inhibition factor.

Two types of radioassay have been developed for the quantification of thyroglobulin autoantibodies, the coprecipitation method, ${ }^{8}$ and the competitive

Accepted for publication 25 February 1981 assay. ${ }^{9}$ These methods have been shown to be very sensitive but require the radiolabelling of either thyroglobulin (in the former method) or thyroglobulin autoantibodies (in the latter). Both assays suffer from the hazards associated with the use of a radioactive label.

With the introduction of the enzyme-linked immunosorbent assay (ELISA) ${ }^{13}$ the detection of antibodies has been facilitated. ${ }^{14}$ However, this method has been applied to very few assays for autoantibodies. ${ }^{1516}$

This paper presents the application of the indirect micro-ELISA method to the investigation of thyroglobulin autoantibodies. The method presented, using microtitre plates, allows the simultaneous assay of 28 specimens in duplicate. It is sensitive, specific, has an objective end-point and the results obtained relate well to those obtained by haemagglutination.

A similar method has recently been described by Voller et al. ${ }^{17}$ The results are similar to those presented in this paper, but these authors conclude that their method lacks the sensitivity of haemagglutination.

\section{Material and methods}

MATERIAL

Microtitre plates: square form polystyrene plates obtained from Dynatech Laboratories Ltd, Daux Road, Billingshurst, Sussex, UK. Although the microtitre plates used have 96 wells, because of inconsistencies in binding characteristics of the peripheral wells, ${ }^{18}$ only the 60 internal wells were used.

Peroxidase-anti-IgG conjugate: obtained as a gift from Dr A Bartlett, Nuffield Laboratories of Comparative Medicine, The Zoological Society of London, Regents Park, London, NW1. 
Buffers: (1) Coating buffer; carbonate/bicarbonate buffer, pH 9.6, $1.59 \mathrm{~g} \mathrm{Na}_{2} \mathrm{CO}_{3}, 2.93 \mathrm{~g}$ $\mathrm{NaHCO}_{2}$ made up to one litre with distilled water. This buffer was prepared freshly every week. (2) Wash buffer; PBS/Tween, pH 7.4, $40 \mathrm{~g} \mathrm{NaCl}, 1 \mathrm{~g}$ $\mathrm{KH}_{2} \mathrm{PO}_{4} 14 \cdot 5 \mathrm{~g} \mathrm{Na} \mathrm{HPO}_{4} .12 \mathrm{H}_{2} \mathrm{O}, 1 \mathrm{~g} \mathrm{KCl}$ and $2.5 \mathrm{ml}$ Tween 20 made up to 5 litres with distilled water. (3) Substrate buffer (for use with orthophenylenediamine substrate); citrate/phosphate buffer, $\mathrm{pH}$ 5.0. $24.3 \mathrm{ml} ; 0.1 M$ citric acid, $25.7 \mathrm{ml} ; 0.2 M$ disodium hydrogen orthophosphate made up to 1 litre.

Substrate for the peroxidase enzyme reaction: orthophenylenediamine (OPD) with hydrogen peroxide. $20 \mathrm{mg}$ OPD was dissolved in $50 \mathrm{ml}$ citrate/ phosphate buffer and $20 \mu \mathrm{H}_{2} \mathrm{O}_{2}$ were added. This solution must be made up freshly immediately before use.

Stopping solution for the enzyme reaction: $2 \cdot 5 \mathrm{M}$ $\mathrm{H}_{2} \mathrm{SO}_{4}$.

Optical densities were measured on a Vitatron UPS universal colorimeter using a $492 \mathrm{~nm}$ filter and micro flow-through cuvette.

Haemagglutination assays were performed using Wellcome Thymune $\mathbf{T}$ and Thymune $M$ Kits. Immunofluorescence was performed using Kallestadt FITC conjugated Goat anti-IgG, -IgA and -IgM sera (Atlantic Antibodies, American Hospital Supply, Station Road, Didcot, Oxon).

Thyroglobulin antigen: Three thyroid glands were removed as soon as possible post mortem from cadavers with no known antemortem thyroid disease, and deep-frozen immediately. Cryostat sections were taken, and investigated for the presence of thyroglobulin autoantibodies, using direct immunofluorescence, with an anti-human IgG serum/ fluorescein isothyocyanate conjugate. All three thyroids were apparently free of antibodies by this method. The thyroglobulin was then extracted from the thyroids and purified by the differential ammonium sulphate precipitation method of Derrien $e t$ al. ${ }^{19}$

In previous experiments, it was shown that thyroglobulin extracts prepared in this way were invariably contaminated by the microsomal antigen. Since the microsomal antigen is particulate, it may be effectively removed from the thyroglobulin preparation by chromatography on Sephacryl S-300 superfine. The extract was therefore chromatographed on a Sephacryl S-300 superfine column, $22 \times 1.6 \mathrm{~cm}$ using phosphate-buffered saline, $\mathrm{pH} 7 \cdot 2,0.15 \mathrm{M}$. Forty fractions, each of $1 \mathrm{ml}$ were collected. The optical density at $210 \mathrm{~nm}$ was measured on a $1 / 5$ dilution of each fraction, and $250 \mu \mathrm{l}$ of a $10^{-2}$ dilution of each fraction (in carbonate/bicarbonate buffer) was incubated in the wells of microtitre plates. For each fraction, three wells were prepared, and the
micro-ELISA procedure outlined below was performed on these, using a serum sample with a high haemagglutination titre, a serum sample with an undetectable haemagglutination titre, or a sample containing buffer only. The positive and negative sera were diluted $1 / 100$.

The elution pattern together with the ELISA optical densities are shown in Fig. 1. From this it may be deduced that, since there is a peak in both the negative serum and buffer graphs at fractions 12 to 19 , this fraction of the thyroglobulin extract is contaminated with IgG. Whether this IgG is autoantibody, attached or unattached to thyroglobulin, is unknown.

The contamination of the eluate with IgG in these fractions was confirmed by radial immunodiffusion against a donkey antihuman IgG antiserum. The results of this experiment are also shown in Fig. 1. The remainder of the eluate showed undetectable concentrations of IgG by this method.

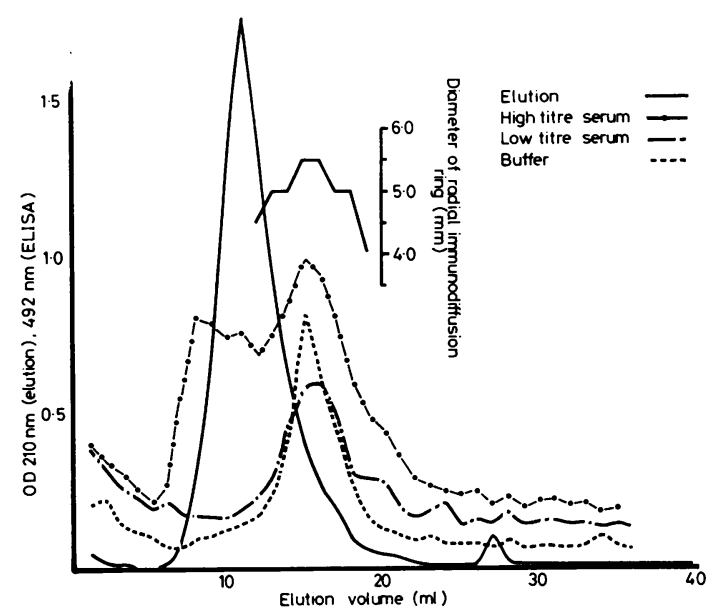

Fig. 1 Chromatography of a thyroglobulin preparation on Sephacryl S-300 superfine. The elution line represents the optical density at $210 \mathrm{~nm}$ obtained from a dilution of each one $\mathrm{ml}$ fraction eluted from the column. The high titre serum, low titre serum, and buffer lines represent the optical densities at $492 \mathrm{~nm}$ obtained after performing an ELISA assay on a dilution of each fraction, as described in the text. The diameters of the radial immunodiffusion (RID) rings obtained by reacting the eluate fractions against a donkey antihuman IgG antiserum are also shown.

It may be seen that the maximum differentiation between the positive and negative sera occurred in fractions 7-11 inclusive. These fractions were pooled, and used as the thyroglobulin antigen. The pooled fractions were divided into $200 \mu \mathrm{l}$ aliquots which 
were deep frozen until used. No deterioration was seen in the antigen in six months.

\section{METHODS}

\section{Basic indirect micro-ELISA methodology}

1 The antigen was diluted in coating buffer, and $250 \mu \mathrm{l}$ were pipetted into the wells of the microtitre plate. The plate was then incubated in a moist chamber for $18 \mathrm{~h}$. Incubation at $37^{\circ} \mathrm{C}$ gave a binding of antigen $47.8 \%$ higher than that at $4^{\circ} \mathrm{C}$, and tended to give more reproducible results (coefficients of variation for $37^{\circ} \mathrm{C}$ and $4^{\circ} \mathrm{C}$ were $2.6 \%$ and $4.5 \%$ respectively).

2 The antigen was poured from the plate, and three washes with the wash buffer carried out, with a three-minute soak at each wash (this procedure was performed by flooding the entire plate with buffer, standing for $3 \mathrm{~min}$ then pouring off the buffer into a sink).

3 The serum samples under investigation were diluted in wash buffer, and $250 \mu \mathrm{l}$ were added to appropriate wells. The plate was incubated in a moist chamber for 3-5 h at room temperature. After this period the plate was emptied and washed as in step 2.

4 The diluted peroxidase-antihuman IgG antiserum was added. The dilution of conjugate used depends upon the required incubation time: with the conjugate used in this study, it was found that a dilution of $2 \times 10^{-3}$ and an incubation time of three hours gave results which were equivalent to those using a dilution of $5 \times 10^{-4}$ with an overnight incubation. (The conjugate was diluted in the wash buffer, and the incubation was carried out at room temperature.)

5 At the end of the incubation period, the plate was again emptied and washed.

6 The substrate solution was made up and $250 \mu \mathrm{l}$ added to each well. After an appropriate time (established by visual inspection of the colour) the reaction was stopped by the addition of $50 \mu \mathrm{l}$ of $2.5 \mathrm{M} \mathrm{H}_{2} \mathrm{SO}_{4}$ to the wells. The enzyme reaction was carried out at room temperature.

7 The optical density of the contents of each well was measured at $492 \mathrm{~nm}$ against a water blank.

\section{OPTIMISATION OF ANTIGEN AND SERUM}

DILUTIONS

In order to investigate the optimum dilutions of both the antigen and the serum samples, they were titrated against each other. Two samples were chosen, one of which was shown by haemagglutination to be negative for thyroid autoantibodies, the other to have a high titre. Dilutions of both samples, from $10^{-1}$ to $10^{-7}$ were then incubated in wells previously coated with dilutions of the thyroglobulin antigen ranging from $10^{-1}$ to $10^{-7}$. After incubating the plate for four hours and washing, peroxidase-labelled antihuman IgG antiserum was added, at a dilution of $5 \times 10^{-3}$, and incubation carried out overnight at room temperature. After washing the plate, the enzyme reaction was carried out, and the optical densities measured. In this way, the ratio of readings for the high and low sera were determined for each dilution of the serum, at each dilution of the antigen preparation. From this titration it was established that the optimum dilutions of antigen and serum were $10^{-3}$ and $10^{-2}$ respectively. The dilution of antigen corresponds to the addition of approximately $300 \mathrm{ng}$ thyroglobulin per well, since the protein concentration of the pooled fractions 7-11 from the chromatographic separation was determined at $1.3 \mathrm{~g} / \mathrm{l}$. The dilution of the peroxidase-linked antiserum was not as critical as the dilutions of antigen and autoantiserum. It is important only that sufficient labelled antiserum should be available to bind to all the available autoimmune IgG. Thus, as mentioned above, dilutions of $2 \times 10^{-3}$ and $5 \times 10^{-4}$ gavesimilar results, with incubation times of three hours and overnight respectively. In this study, only autoantibodies of the " $G$ " class were investigated. It has been shown ${ }^{20}$ that the majority of autoantibodies occur in this class.

\section{Results}

The results of the indirect micro-ELISA method used in this study are expressed in terms of a ratio of the optical density of the test serum to that obtained from a pooled serum established as negative for thyroid autoantibody activity by haemagglutination, immunofluorescence, and the biochemical and clinical euthyroidism of the donors. The optical density obtained from a well containing buffer only is subtracted from all the optical densities before this ratio is obtained. The validity of this means of expressing the results is discussed later.

Serum samples from laboratory personnel and outpatients with no biochemical or clinical evidence or family history of thyroid disease were assayed. The mean OD ratio obtained from these samples was $1 \cdot 06$, with a range $( \pm 2$ SD) of 0.09 to $2 \cdot 20(n=61)$.

The within-batch precision of the method was $4.5 \%$ (coefficient of variation) and the betweenbatch precision was assessed on seven normal sera and two sera with raised concentrations, in six separate assays. The results of the latter are shown in Table 1. (The results from serum 28 contain one outlier.)

In order to establish the validity of the method, a number of samples which had previously been assayed by the haemagglutination method were 
Table 1 Between-batch precision of ELISA method for thyroglobulin autoantibodies

\begin{tabular}{lclc}
\hline Serum & $\begin{array}{l}\text { Mean } \\
\text { OD ratio }\end{array}$ & $\begin{array}{l}\text { Standard } \\
\text { deviation }\end{array}$ & $\begin{array}{l}\text { Coefficient } \\
\text { of variation (\%) }\end{array}$ \\
\hline CRS & 0.95 & 0.36 & 3.82 \\
PC & 1.46 & 0.15 & 10.40 \\
PM & 0.94 & 0.05 & 5.40 \\
RG & 1.38 & 0.13 & 9.08 \\
MJ & 0.99 & 0.07 & 7.14 \\
9 & 2.08 & 0.12 & 5.76 \\
28 & 1.40 & 0.36 & 25.60 \\
A & 24.77 & 1.88 & 7.57 \\
C & 6.95 & 0.44 & 6.39 \\
\hline
\end{tabular}

assayed by the new system.

The results of the comparison are shown in Fig. 2. It will be seen from this graph that although there is a general agreement in the results, some discrepancies occur.

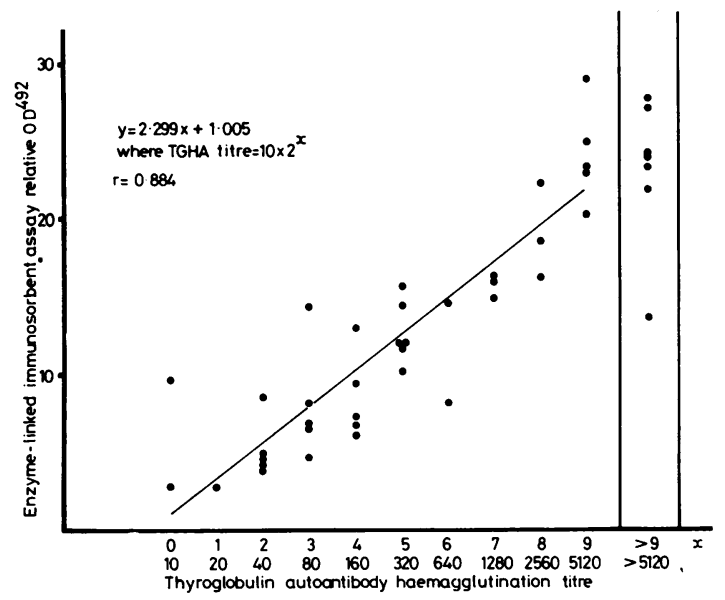

Fig. 2 Correlation of thyroglobulin autoantibody results obtained by TGHA and ELISA.

Inactivation of complement by treatment of serum samples at $60^{\circ} \mathrm{C}$ for $30 \mathrm{~min}$ is necessary before performing the haemagglutination assay. This treatment is unnecessary for the ELISA procedure. Heat inactivation has been shown to give lower results in an ELISA method for thyroglobulin. ${ }^{21}$

No significant difference was found between results obtained using serum and plasma (with heparin or sequestrene as anticoagulant) the autoantibody activity in serum maintained at $-20^{\circ} \mathrm{C}$ was unchanged after three months. Repeated freezing and thawing, however, resulted in a reduction in the optical density ratio, particularly with plasma samples.

Throughout this study, results were expressed in the form of the optical density ratio as shown pre- viously. In the indirect micro-ELISA method for antibodies against infectious diseases, this is the recommended procedure for expressing results, since variations of binding affinities of antibody species make the expression of results, in concentration terms, dubious. ${ }^{22}$

As a simple test of the variation of binding affinities of these autoantibodies, three serum samples with different titres of thyroglobulin autoantibodies, and five serum samples with no detectable antithyroglobulin activity were assayed in serial tenfold dilutions, from $10^{-1}$ to $10^{-6}$. Using the graphs obtained, a logit/log transform was performed, and the slopes of the lines obtained were taken to give an approximation of the affinity of binding of each serum. The results are shown in Table 2. The experiment demonstrated a variation in slope of the logit/log line, as suggested for non-autoimmune antibodies. The results are discussed later.

Table 2 Variation in slope of logit/log transform obtained from a plot of $O D$ ratio against dilution factor for autoimmune and non-autoimmune serum samples

\begin{tabular}{lll}
\hline $\begin{array}{l}\text { TGHA } \\
\text { titre }\end{array}$ & $\begin{array}{l}\text { Slope of logit/log } \\
\text { transform }\end{array}$ & $\begin{array}{l}\text { Correlation } \\
\text { coefficient }\end{array}$ \\
\hline$<10$ & 4.61 & 0.997 \\
$<10$ & 4.74 & 0.963 \\
$<10$ & 3.59 & 0.993 \\
$<10$ & 3.27 & 0.999 \\
$<10$ & 5.82 & 0.921 \\
$>5120$ & 6.00 & 0.992 \\
160 & 3.67 & 0.992 \\
1280 & 2.94 & 0.995 \\
\hline
\end{tabular}

TGHA = thyroglobulin autoantibody haemagglutination.

In order to test the specificity of the method serum samples with negative or very low thyroglobulin autoantibody titres by haemagglutination (TGHA) and high concentrations of thyroid microsomal autoantibody (MCHA), or antinuclear factor (ANA) were assayed. The results correlated well with the thyroglobulin haemagglutination results and showed no increase in OD ratio as a result of the presence of the microsomal or antinuclear antibody. The results are shown in Table 3.

\section{Discussion}

The results obtained in this study suggest that the indirect micro-ELISA method is applicable to the assay of thyroglobulin directed autoantibodies. Assessing the validity of the method is difficult since the only established method for detecting and quantifying autoantibodies is haemagglutination, and this method suffers from a number of drawbacks, as already outlined; it seems possible that the inade- 
Table 3 ELISA results obtained from serum samples containing microsomal or antinuclear autoantibodies

\begin{tabular}{lrrrl}
\hline Sample & $\begin{array}{l}\text { TGHA } \\
\text { titre }\end{array}$ & $\begin{array}{l}\text { MCHA } \\
\text { titre }\end{array}$ & $\begin{array}{l}\text { ANA } \\
\text { titre }\end{array}$ & $\begin{array}{l}\text { ELISA } \\
\text { OD ratio }\end{array}$ \\
\hline 1 & $<10$ & $20^{2}$ & - & $1 \cdot 00$ \\
2 & $<10$ & $80^{2}$ & - & 0.67 \\
3 & 10 & $80^{2}$ & - & $2 \cdot 67$ \\
4 & $<10$ & $<10^{2}$ & 80 & $1 \cdot 17$ \\
5 & $<10$ & $40^{2}$ & - & $1 \cdot 17$ \\
6 & 40 & $320^{2}$ & - & $5 \cdot 00$ \\
7 & 10 & $<10^{2}$ & 1280 & $2 \cdot 67$ \\
8 & 20 & $10^{2}$ & 320 & 3.33 \\
9 & 20 & $<10^{2}$ & - & 2.67 \\
10 & $<10$ & $40^{2}$ & - & 1.00 \\
11 & 20 & $<10^{2}$ & 160 & 2.00 \\
12 & $<10$ & $<10^{2}$ & 320 & 1.00 \\
\hline
\end{tabular}

TGHA = thyroglobulin autoantibody haemagglutination. MCHA = thyroid microsomal autoantibody.

ANA $=$ antinuclear factor.

quacies of the haemagglutination method may be responsible for some of the anomalies seen in the comparison of results of the two methods. In this laboratory, inter-observer variation in reading haemagglutination titres have varied by factors as high as 4-that is, $1: 40$ to $1: 160$.

The use of a standard curve, expressed either in terms of units of autoantibody activity or in mass terms would be useful in this type of assay. Although Voller et al. ${ }^{22}$ do not consider the use of such a standard curve valid for antibodies to infectious diseases, Endo et al. ${ }^{16}$ use such a method for the quantification of thyroid autoantibodies. In our study, the validity of the use of such a curve was not proven. However, it would seem that the use of a standard curve in future assays might be preferential, since the method most commonly used, the optical density ratio, has the inherent implication of a linear dose response relation. Felgner ${ }^{23}$ has suggested the use of the multiple of normal activity (MONA) for expressing indirect micro-ELISA results, which takes some account of the affinity of binding of the antibodies.

Voller et al. ${ }^{17}$ have recently published a similar method to that described here. They, however, concluded that the method is not as sensitive as existing methods, particularly haemagglutination.

The term sensitivity describes the ability of the system to discriminate between samples with very low concentrations of autoantibody and those which are negative. To test the sensitivity of the ELISA method by comparing it only with haemagglutination may be misleading for three reasons:

(i) It is well established that low haemagglutination titres $(<1: 80)$ are considered clinically insignificant, and serum samples with low titres may often show a negative reaction in the indirect immunofluorescence assay, suggesting that the haemagglutination methods may give false-positives.

(ii) Sensitivity is dependent upon the precision of the method, and the precision of haemagglutination methods is not very good, mainly because of interand intra-observer variation in end-point identification, and also because of dilution errors, particularly when Taketsy loops are used.

(iii) Haemagglutination methods will detect only those antibodies with agglutinating properties. In the method by Voller et al., it would appear that a sheep antibody to all classes of human immunoglobulins was used, which may allow the detection of nonagglutinating autoantibodies, thus giving an apparent false high result with a low titre haemagglutination result.

Because of these potential difficulties associated with the use of haemagglutination as a reference method, it may be advisable in future studies to test the sensitivity of this type of assay against the indirect immunofluorescence method, which is extremely sensitive, an established radioassay, and also to assess thoroughly the clinical state of each individual. Comparison with haemagglutination results, however, should still be carried out.

Endo et al. ${ }^{16}$ present two methods for the detection of thyroglobulin autoantibodies, one similar to this method (but using a fluorimetrically detected endpoint), the other using enzyme-labelled thyroglobulin instead of enzyme-labelled antihuman IgG serum. They suggest that the latter method is the better in terms of sensitivity, but this method requires the preparation of thyroglobulin/enzyme conjugate, which is not yet available commercially. Additionally the method uses latex rubber-strings as the solid phase, and although this gives good binding characteristics, it requires careful handling in washing procedures. In the microtitre plate method, washing is a rapid, easily performed procedure which is applied to all wells equally and simultaneously.

Methods using microtitre plates may also be automated to various degrees using microtitre plate ELISA washers and readers, or the fully automated micro-ELISA processors currently available.

\section{References}

${ }^{1}$ Owen CA. A review of "auto-immunisation" in Hashimoto's disease. J Clin Endocrinol Metab 1958;18: 1015-23.

2 Doniach D, Roitt IM. Autoimmunity in Hashimoto's disease and its implications. $J$ Clin Endocrinol Metab 1957;17:1293-1304.

3 Trotter WR, Belyavin G, Waddams A. Precipitating and complement-fixing antibodies in Hashimoto's disease. Proc R Soc Med 1957;50:961-2.

${ }^{4}$ Philip JR, Weir DM, Stuart AE, Irvine WJ. A latex particle precipitation test in the diagnosis of thyroid 
disease. J Clin Pathol 1962;15:148-52.

${ }^{5}$ Doniach D. Thyroid autoimmune disease: symposium on thyroid gland, 1966. J Clin Pathol 1967;20:385-90.

${ }^{6}$ Holborrow J, Brown PC, Roitt IM, Doniach D. Cytoplasmic localisation of complement-fixing auto-antigen in human thyroid epithelium. Br J Exp Pathol 1959;40: 583-8.

' Fulthorpe AJ, Roitt IM, Doniach D, Couchman K. A stable sheep cell preparation for detecting thyroglobulin auto-antibodies and its clinical applications. J Clin Pathol 1961 ;14:654-60.

${ }^{8}$ Bodleander P, Arjouilla JR, Twomey SL. Sensitive radioimmunological screening test for anti thyroglobulin auto-antibodies. Clin Chem 1978;24:272-4.

${ }^{9}$ Mori T, Fisher J, Kriss JP. Studies of an in vitro binding reaction between thyroid microsomes and long acting thyroid stimulator globulin (LATS): 1 Development of solid-state competitive binding radioassay methods for measurement of antimicrosomal and antithyroglobulin antibodies. J Clin Endocrinol Metab 1970;31:119-33.

${ }^{10}$ Corkhill JE. Counterimmunoelectrophoresis. IMLS Curr Top Med Lab Sci 1977;2 :i-xiii.

${ }^{11}$ Anderson JR, Buchanan WW, Goudie RB, Gray KG. Diagnostic tests for thyroid antibodies : a comparison of the precipitin and latex-fixation tests. J Clin Pathol 1962; $15: 462-71$.

12 Wilkin TJ, Swanson Beck J, Hayes PC, Potts RC, Young R. A passive haemagglutination (TRC) inhibitor in thyrotoxic serum. J Clin Endocrinol 1979;10:507-14.

${ }^{13}$ Engvall E, Perlmann P. Enzyme-linked immunosorbent assay (ELISA) quantitative assay of immunoglobulin G. Immunochemistry $1971 ; 8: 871-4$.

14 Voller A, Bidwell DE, Bartlett A. Enzyme immunoassays in diagnostic medicine. Bull WHO 1976;53:55-65.

15 Pesce AJ, Mendoza N, Boreisha I, Gaizuris MA, Pollack
VE. Use of enzyme-linked antibodies to measure serum anti-DNA antibody in systemic lupus erythematosus. Clin Chem 1974;20:353-9.

16 Endo Y, Nakano J, Horinouchi K, et al. An enzyme immunoassay for the measurement of anti-thyroglobulin autoantibody in human serum. Clin Chim Acta 1980; 103:67-77.

17 Voller A, Bidwell DE, Burek CL. An enzyme linked immunosorbent assay (ELISA) for antibodies to thyroglobulin. Proc Soc Exp Biol Med 1980;163:402-5.

${ }^{18}$ Krika L, Carter TJ, Burt SM, et al. Variability in adsorption properties of microtitre plates used as solid supports in enzyme immunoassay. Clin Chem 1980;26:741-4.

19 Derrien Y, Roche J. Recherches sur la preparation et les proprietes de la thyroglobuline pure. Biochim Biophys Acta $1948 ; 2: 454-70$.

20 Torrigiani G, Roitt IM, Doniach D. Quantitative distribution of human thyroglobulin autoantibodies in different immunoglobulin classes. Clin Exp Immunol 1968;3: 621-30.

${ }^{21}$ Endo Y, Nakano J, Ohtaki S, et al. An enzyme immunoassay for the measurement of thyroglobulin in human serum. Clin Chim Acta 1979;95:325-36.

22 Voller A, Bidwell DE, Bartlett A. The enzyme linked immunosorbent assay (ELISA) Dynatech Europe, 1979: 30-3.

${ }^{23}$ Felgner P. Stepless antibody determination with the stickELISA technique. Results expressed as multiple of normal activity (MONA) $\mathrm{Zbl} \mathrm{Bakr} \mathrm{Hyg} \mathrm{1.} \mathrm{Abt} \mathrm{Orig}$ $1978 ; A 242,100-5$.

Requests for reprints to: Mr R Goodburn, Department of Pathology, Ashford Hospital, London Road, Ashford, Middlesex TW15 3AA, England. 